\title{
Chediak-Higashi syndrome associated with maternal uniparental isodisomy of chromosome 1
}

\author{
Rémi Dufourcq-Lagelouse ${ }^{1}$, Nathalie Lambert ${ }^{1}$, Michel Duval ${ }^{2}$, Géraldine Viot $^{3}$, \\ Etienne Vilmer ${ }^{2}$, Alain Fischer ${ }^{1}$, Marguerite Prieur ${ }^{3}$ and Geneviève de Saint Basile ${ }^{1}$ \\ ${ }^{1}$ Unité de Recherches sur le développement normal et pathologique du système immunitaire INSERM U429, Hôpital \\ Necker-Enfants Malades \\ ${ }^{2}$ Unité d'Hématologie-Immunologie, Hôpital Robert Debré \\ ${ }^{3}$ Laboratoire de cytogénétique, Hôpital Necker-Enfants Malades, Paris, France
}

\begin{abstract}
Chediak-Higashi syndrome (CHS) is a rare autosomal recessive disorder (incidence around 1 in $10^{6}$ births), characterised by a complex immunologic defects, reduced pigmentation, and presence of giant granules in many different cell types. It most likely results from defective organellar trafficking or protein sorting. The causative gene (LYST) has recently been identified and shown to be homologous to the beige locus in the mouse. CHS has always been reported associated with premature-termination-codon mutations in both alleles of LYST. We report a unique patient with CHS, who was homozygous for a stop codon in the LYST gene on chromosome 1 and who had a normal 46,XY karyotype. The mother was found to be a carrier of the mutation, whereas the father had two normal LYST alleles. Non-paternity was excluded by the analysis of microsatellite markers from different chromosomes. The results of $\mathbf{1 3}$ informative microsatellite markers spanning the entire chromosome 1 revealed that the proband had a maternal isodisomy of chromosome 1 encompassing the LYST mutation. The proband's clinical presentation also confirms the absence of imprinted genes on chromosome 1.
\end{abstract}

Keywords: Chediak-Higashi syndrome; maternal isodisomy; chromosome 1; LYST mutation

\section{Introduction}

Chediak-Higashi syndrome (CHS) (MIM: 214500) is a rare autosomal recessive immune disease, characterised by a partial oculocutaneous albinism, a predisposition to pyogenic infections and the presence of large granules in many cell types. ${ }^{1,2}$ Unless treated by bone

Correspondence: Geneviève de Saint Basile, INSERM U429, Hôpital Necker-Enfants Malades, 149 rue de Sèvres, 75743 Paris Cedex 15, France. Tel: 33144495080 ; Fax: 33142730640 ; E-mail: sbasile@necker.fr

Received 11 February 1999; revised 26 March 1999; accepted 12 April 1999 marrow transplantation, death usually occurs in childhood from a lymphohistiocytic syndrome, the so-called 'accelerated phase' of the disorder, though some patients have a relatively milder clinical course. ${ }^{3}$ The hallmark of CHS is the presence of giant organelleslysosomes, melanosomes and giant inclusion bodies seen in virtually all granulated cells. ${ }^{2}$ The $C H S$ gene product is likely to be involved in the biogenesis, structure, or function of these different organelles, possibly in organelle trafficking or protein sorting to organelles. ${ }^{4} \mathrm{~A}$ similar disorder occurs in a wide variety of mammalian species, most importantly, the beige mouse which shares many features with human CHS. ${ }^{5}$ 
The CHS locus was mapped to chromosomal band $1 \mathrm{q} 42-43^{6,7}$ and the disease gene (LYST) was identified by its homology to the mouse beige gene. ${ }^{8,9}$ This gene encodes a large cytosolic as well as microtubule associated protein. ${ }^{4,9,10}$ The precise function of LYST, however, remains unknown. Mutation analyses of the CHS gene have been somewhat hindered by the large size of the CHS cDNA $(13.5 \mathrm{~kb})$, and thus far, only eight pathologic mutations have been identified, all of which leading to a truncated CHS protein. ${ }^{9,11,12}$

We herein report the case of a cytogenetically normal male affected with CHS as a result of homozygosity for mutation of the LYST gene. Homozygosity for the LYST gene was the result of maternal disomy of the entire chromosome 1 . The proband's clinical presentation is consistent with the absence of imprinted genes on maternal chromosome 1.

\section{Subjects and Methods}

\section{Case Report}

The proband (VA) was a $3200 \mathrm{~g}$ male, the eldest child of healthy unrelated parents. The mother was 24 and the father 27 years old at the patient's birth. The proband had one younger, clinically unaffected sister. The pregnancy, labour, and delivery were uncomplicated. Diagnosis of ChediakHigashi syndrome was performed at the age of $5 \frac{1}{2}$ years in the proband when he developed features characteristic of an accelerated phase of the disease. These included fever, oedema, hepatosplenomegaly, lymphadenopathy, pancytopenia, coagulation disorder and infiltration of most organs by lymphocytes and histiocytes. In addition, the patient presented with a partial oculocutaneous albinism, whilst giant granulations were detected in his leukocytes. Postnatal physical and mental development were totally normal. At this age, height was $108.5 \mathrm{~cm}$, and weight was $20 \mathrm{~kg}$. The child died at 6 years of age from veino-occlusive disease following a bone marrow transplantation attempt.

\section{Conventional and Molecular Cytogenetics}

Routine chromosome analysis of the proband was performed on RHG and GTG banded metaphases from B-EBV lymphoblastoid cell line. RBG banding was also performed on prometaphases from a FdU synchronised lymphoblastoid cell line by using a terminal 5-bromo-2'-deoxyuridine (BrDU) pulse for at least 7 hours of culture. Twelve metaphases were analysed. Fluorescence in situ hybridisation (FISH) analysis was performed with a chromosome 1q42-q43 specific probe (YAC 906H7, locus D1S235), closely linked to the $C H S$ locus. This probe was amplified by $A l u$-PCR using the $A l u$ specific primers, Alu278:5'-GGCCTCCCAAAGTGCTGGGATTACAGGC-3' and AluIV: 5'-CGACAGAGCAGACTCCGTCTCA-3', and biotin-16-dUTP labelled by nick translation according to the Boehringer Mannheim protocol. The detection of the probe was performed with three amplification steps (Avidin-Texas red; Avidin-Biotin; AvidinTexas red). Chromosomes were counterstained with DAPI.

\section{Molecular Investigations}

After appropriate informed consent, genomic DNAs from the proband and his parents, isolated from peripheral blood, were analysed with the polymorphic markers depicted in Figure 1 and Table 1 as previously described. ${ }^{6}$ Non-paternity was tested by the use of nine microsatellite markers from five different chromosomes. The results of the informative markers are reported in Table 1. For mutation analysis of the LYST gene, cDNA was prepared from blood cell proband, amplified by PCR in nine overlapping fragments covering the entire sequence. These fragments were subject to a protein truncation test (PTT) analysis (manuscript in preparation). PCR product leading to a transcribed fragment of abnormal size was then directly sequenced. In the parents, sequence analysis was performed on a $150 \mathrm{bp}$ PCR fragment DNA encompassing the mutation region.

\section{Results}

The proband was a 6-year-old male from a non consanguineous family with a clinical presentation of Chediak-Higashi syndrome. He was referred during an accelerated phase of the disease. Several polymorphic DNA markers from 1q42-q43 region containing the Chediak-Higashi gene were evaluated. Markers D1S2649, D1S235 and D1S2680 flanking the gene in a $2 \mathrm{cM}$ region, were completely informative and revealed only one maternal allele (presumably present in two copies) and no paternal alleles in the propositus (Figure 1). In contrast, both maternal and paternal alleles were detected in his healthy sister. Ten additional microsatellite markers spanning the length of chromosome 1 which were partly or fully informative, were analysed in the parents and the proband. The proband was homozygous for all these markers. In each case, inheritance of one maternal allele was detected. Analysis of the proband and his parents with several polymorphic markers from other chromosomes showed typical Mendelian inheritance, with paternal and maternal alleles detected in the proband (Table 1).

Cytogenetic analysis of the patient using RHG, GTG, and RBG banding of metaphases and prophases from a lymphoblastoid cell line showed a normal 46,XY karyotype. FISH study with YAC 906H7 showed a fluorescent signal on each chromosome 1, confirming the absence of deletion of D1S235 locus (data not shown).

A Protein Truncated Test ${ }^{13}$ was established to analyse the LYST gene in several patients with ChediakHigashi syndrome (manuscript in preparation). This test enabled us to identify in the proband, a shorter protein than the one observed in controls in vitro translation assay of a PCR fragment. The latter 

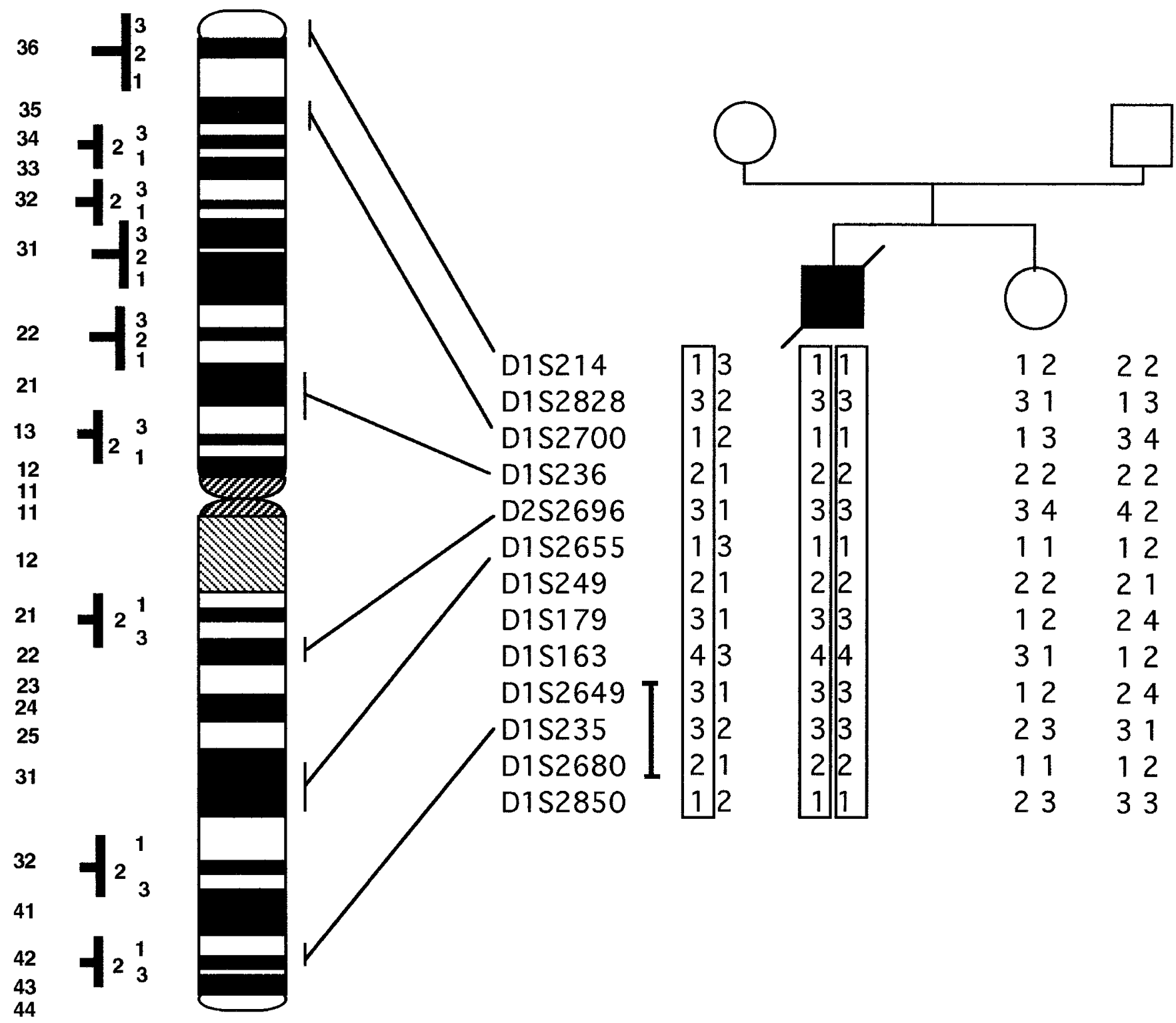

Figure 1 Idiogram of chromosome 1. Result of the allelic distribution of 13 informative polymorphic markers spanning the chromosome 1 in the different members of the CHS family. Localisation of the markers relative to $G$ bands are shown on the left.

Table 1 Microsatellite marker segregation in the proband and his parents

\begin{tabular}{lccc}
\hline Locus & Proband & Father & Mother \\
\hline D10S1645 & 34 & 32 & 14 \\
D10S195 & 32 & 33 & 12 \\
D15S962 & 23 & 23 & 13 \\
\hline
\end{tabular}

corresponded to nucleotides 2452 to 3886 of the LYST sequence $^{9}$ (data not shown). Direct sequencing of this fragment revealed an homozygous $\mathrm{T}$ deletion between nucleotide position 2620-2623 (Figure 2), leading to a termination codon at amino acid position 898 . Sequencing of this region from the parents' DNA confirmed that the mother was heterozygous for this mutation, whereas no mutation was detected in the father's DNA (Figure 2). 


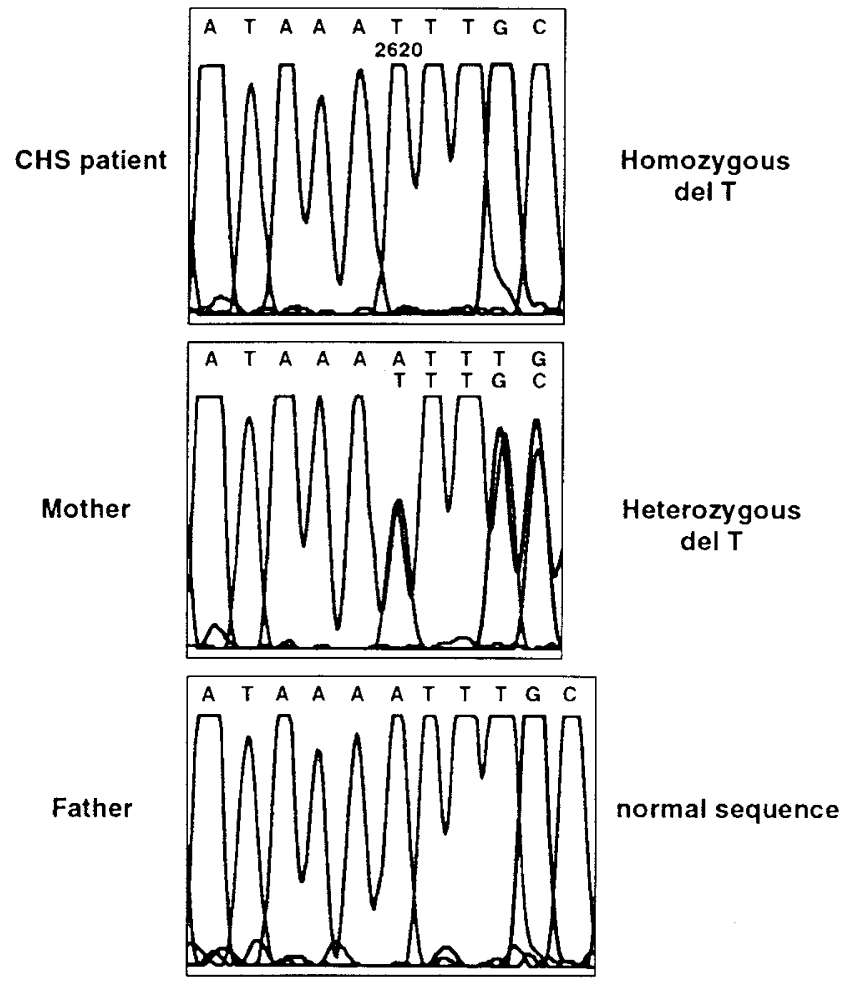

Figure 2 Results of direct automated nucleotide sequencing using a reverse primer. The patient's PCR product was homozygous for a $T$ deletion (identified as ' $\mathrm{A}$ ' in the complementary sequence shown here) at nucleotide position 2620 , resulting in a termination codon at position 898 . The mother's PCR product was heterozygous for the same deletion with visualisation of one base pair shifting of the corresponding allele sequence following the deletion. Normal sequence was detected in the father's PCR product.

\section{Discussion}

In the course of the molecular analysis of a nonconsanguineous CHS family, genotyping with polymorphic DNA markers from $1 \mathrm{q} 43$ revealed that the affected child had inherited a maternal haplotype but no paternal haplotype. The same results were obtained for all the tested markers belonging to $1 p$ and more centromeric 1q region, whereas both parental haplotypes were identified for the other chromosomes. Cytogenetic study as well as in situ hybridisation analysis failed to reveal any abnormalities of chromosome 1 , especially in the $\mathrm{q} 42-\mathrm{q} 43$ region. Mutation analysis detected an homozygous base pair deletion in the patient LYST gene leading to a frameshift and subsequent stop codon which was present as an heterozygous mutation in the mother's DNA and absent in the father's. Therefore, it was concluded that CHS in this patient resulted from maternal uniparental isodisomy from chromosome 1 with inheritance of two copies of a LYST mutation carried by the mother.

Patient chromosome 1 displayed homozygosity for all the marker loci examined. Although several mechanisms may lead to the occurrence of uniparental disomy (UPD), maternal isodisomy detected in this patient most probably results from the fertilisation by a nullisomic paternal gamete of a monosomic maternal gamete mutated in the LYST gene, followed by a postzygotic duplication of the maternal chromosome 1 . Other UPD mechanisms, ie non-disjunction events during meiosis I or II in one parent, followed by gametic complementation, or trisomy rescue ${ }^{14,15}$ will lead to heterodisomy. This is the third case of chromosome 1 maternal UPD, ${ }^{16,17}$ whilst only one chromosome 1 paternal UPD has been reported so far. ${ }^{18}$ Although this represent a small sample size, this difference might alternatively be related to the high frequency of chromosome 1 paternal nullisomy $(0.25 \%)$ observed in the population. ${ }^{19}$ Single chromosome duplication increases the risk of homozygosity for deleterious recessive genes. It provides a unique genetic mechanism for inheritance of autosomal recessive disease from a single carrier parent. Such a phenomenon has previously been described in several conditions ${ }^{20}$ including cartilage hair hypoplasia on chromosome $9,{ }^{21}$ familial Mediterranean fever on chromosome $16^{22}$ or Duchenne muscular dystrophy on chromosome $\mathrm{X} .^{23}$ Chediak-Higashi syndrome is a rare autosomal recessive disorder whose frequency is estimated to be $1 / 10^{6}$ birth. The majority of the cases were born in consanguineous families. Occurrence of this syndrome in non-consanguineous families, as the case reported here, should lead to considering UPD as a possible mechanism of a rare disease expression. Recognition of such a mechanism would have important implication in further genetic counselling in these families. In this family, Mendelian inheritance would have predicted a risk of $1 / 4$, whereas the actual risk of recurrence is almost zero.

Apart from the Chediak-Higashi syndrome, the patient has no other unusual conditions. He had a fullterm birth weight of $3200 \mathrm{~g}$, without indications of either intrauterine growth retardation, dysmorphic features, or developmental abnormalities. This strengthens the observation made in two other settings which suggests that there are no imprinted gene(s) in maternally derived chromosome $1{ }^{16,17}$ In the first reported case, absence of imprinting was observed in a 2-month-old infant ${ }^{17}$ and in a young adult in the second 
case. ${ }^{16}$ Pericentromeric heterodisomy with partial isodisomy characterised these two latter cases, whereas the paternal chromosome 1 UPD reported has pericentromeric isodisomy and distal heterodisomy. The patient described here has isodisomy of the entire chromosome 1, but no apparent additional phenotypic consequence seems to result from this genetic difference.

\section{Acknowledgements}

We are grateful to Stéphanie Certain and Liliane Allard for excellent technical assistance. This work was supported in part by grants from l'Institut National de la Santé et de la Recherche Médicale (INSERM), l'Association Vaincre les Maladies Lysosomiales (VML) and l'Association Française contre les Myopathies (AFM). RDL and NL contributed equally to this study.

\section{References}

1 Beguez-Cesar A: Neutropenia cronica maligna familiar con granulaciones atipicas de los leucocitos. Sociedad cubana de pediatr boletin 1943; 15: 900-922.

2 Blume R, Wolff S: The Chediak-Higashi syndrome: studies in four patients and a review of the literature. Medicine 1972; 51: 247-280.

3 Spritz RA: Genetic defects in Chediak-Higashi syndrome and the beige mouse. J Clin Immunol 1998; 18: 97-105.

4 Faigle W, Raposo G, Tenza D et al: Deficient peptide loading and MHC class II endosomal sorting in a human genetic immunodeficiency disease: the chediak-higashi syndrome [In Process Citation]. J Cell Biol 1998; 141: 1121-1134.

5 Windhorst DB, Padgett G: The Chediak-Higashi syndrome and the homologous trait in animals. $J$ Invest Dermatol 1973; 60: 529-537.

6 Barrat FJ, Auloge L, Pastural E et al: Genetic and physical mapping of the Chediak-Higashi syndrome on $\mathrm{Chr}$ 1q42-43. Am J Hum Genet 1996; 59: 625-632.

7 Fukai K, Oh J, Karim MA et al: Homozygosity mapping of the gene for the Chediak-Higashi syndrome to 1q42-q44 in a segment of conserved syntheny that includes the mouse beige locus (bg). Am J Hum Genet 1996; 59: 620-624.

8 Barbosa MDFS, Nguyen QA, Tchernev VT et al: Identification of the homologous beige and Chediak-Higashi syndrome genes. Nature 1996; 382: 262-265.

9 Nagle DL, Karim AM, Woolf EA et al: Identification and mutation analysis of the complete gene for ChediakHigashi syndrome. Nat Genet 1996; 14: 307-311.
10 Perou CM, Leslie JD, Green W, Li L, Ward DM, Kaplan J: The Beige/Chediak-Higashi syndrome gene encodes a widely expressed cytosolic protein. J Biol Chem 1997; 272: 29790-29794

11 Barbosa MDFS, Barrat FJ, Tchernev VT et al: Identification of mutations in two major mRNA isoforms of the Chediak-Higashi syndrome gene in human and mouse. Hum Mol Genet 1997; 6: 1091-1098.

12 Karim MA, Nagle DL, Kandil HH, Burger J, Moore KJ, Spritz RA: Mutations in the Chediak-Higashi syndrome gene (CHS1) indicate requirement for the complete 3801 amino acid CHS protein. Hum Mol Genet 1997; 6: 1087-1089.

13 Hogervorst FB, Cornelis RS, Bout M et al: Rapid detection of BRCA1 mutations by the protein truncation test. Nat Genet 1995; 10: 208-212.

14 Engel E: Uniparental disomy revisited: the first twelve years. Am J Med Genet 1993; 46: 670-674.

15 Ledbetter DH, Engel E: Uniparental disomy in humans: development of an imprinting map and its implications for prenatal diagnosis. Hum Mol Genet 1995; 4: 1757-1764.

16 Field LL, Tobias R, Robinson WP, Paisey R, Bain S: Maternal uniparental disomy of chromosome 1 with no apparent phenotypic effects [letter] [see comments]. Am J Hum Genet 1998; 63: 1216-1220.

17 Pulkkinen L, Bullrich F, Czarnecki P, Weiss L, Uitto J: Maternal uniparental disomy of chromosome 1 with reduction to homozygosity of the LAMB3 locus in a patient with Herlitz junctional epidermolysis bullosa. Am J Hum Genet 1997; 61: 611-619.

18 Gelb BD, Willner JP, Dunn TM et al: Paternal uniparental disomy for chromosome 1 revealed by molecular analysis of a patient with pycnodysostosis. Am J Hum Genet 1998; 62: $848-854$

19 Martin R, Spriggs E, Ko E, Rademaker A: The relationship between paternal age, sex ratio, and aneuploidy frequencies in human sperm, as assessed by multicolor FISH. Am J Hum Genet 1995; 57: 1395-1399.

20 Engel E: Uniparental disomies in unselected populations. Am J Hum Genet 1998; 63: 962-966.

21 Sulisalo T, Makitie O, Sistonen P et al: Uniparental disomy in cartilage-hair hypoplasia. Eur J Hum Genet 1997; 5 $35-42$.

22 Korenstein A, Ravia Y, Avivi L: Uniparental disomy of chromosome 16 in offsprings of familial Mediterranean fever (FMF) patients treated with colchicine. Am J Hum Genet 1994; (Suppl) 55: A109.

23 Quan F, Janas J, Toth-Fejel S, Johnson DB, Wolford JK, Popovich BW: Uniparental disomy of the entire X chromosome in a female with Duchenne muscular dystrophy. Am J Hum Genet 1997; 60: 160-165. 